\title{
Kesesuaian Lahan Peneluran Penyu Lekang Lepidochelys olivacea, Eschscholtz, 1829 (Reptilia:Cheloniidae) di Pantai Mapak Indah, Nusa Tenggara Barat
}

\author{
Mochamad Rizaldi Akbar*, Oktiyas Muzaky Luthfi, M. Barmawi \\ Program Studi IImu Kelautan, Fakultas Perikanan dan Ilmu Kelautan, Universitas Brawijaya \\ Jl. Veteran , Malang, Jawa Timur 65145, Indonesia \\ *Corresponding author, e-mail : rizaldi293@gmail.com
}

\begin{abstract}
ABSTRAK : Pantai Mapak Indah merupakan pantai yang sering menjadi pantai pendaratan biota Penyu, umumnya penyu yang mendarat berjenis penyu Lekang (Lepidochelys olivaceae), pantai yang juga di gunakan untuk aktifitas nelayan dan pariwisata diduga akan mengganggu habitat penyu yang cenderung merusak atau merubahnya. Tujuan dari penelitian ini adalah untuk mengetahui habitat yang sesuai untuk kebutuhan peneluran penyu Lekang (Lepidochelys olivaceae). Metode yang di pakai menggunakan data Primer (Suhu, Kelembaban, Kemiringan, dan Vegetasi) dan skunder berasal dari catatan kelompok pelestari penyu dan instansi terkait. Penelitian ini di laksanakan pada tanggal 24 Juni - 05 Agustus 2019. Hasil dari penelitan ini adalah rentang kemiringan pantai mencapai 10.5\%-26\% dengan rata-rata $16.3 \%$ masih dalam kategori Agak Curam, untuk perbandingan komposisi pasir di sarang Alami dan Semi-Alami 92,94\% \& 96,34\%, vegetasi yang di temukan di sekitar pantai adalah cemara Udang (Casuarina Equisetifolia) dan Pandan Laut (Pandanus sp.), kelapa (Cocos Nucifera) dan Katang-katang (Ipomoea pes-caprae). Suhu saat di lakukan pengamatan selama seminggu memiliki rentang $25^{\circ}$ $28^{\circ}$ hal ini dapat mempengaruhi jenis kelamin Tukik yang akan menetas serta lama inkubasinya di dalam sarang Semi-Alami
\end{abstract}

Kata Kunci: Habitat Peneluran; Penyu Lekang; Lepidochelys olivaceae; Pantai Mapak Indah

\section{Land Suitability of Lepidochelys olivacea, Eschscholtz, 1829 (Reptilia:Cheloniidae) in Mapak Indah Beach, West Nusa Tenggara}

\begin{abstract}
Mapak Indah Beach is a beach that is often used as a landing site for sea turtles, generally turtles that land on the type of Lekang turtle (Lepidochelys olivaceae), a beach that is also used for fishing and tourism activities is thought to disturb turtle habitats that tend to damage or change it. The purpose of this study was to determine the suitable habitat for the needs of Lekang turtle nesting (Lepidochelys olivaceae). The method used uses Primary data (Temperature, Humidity, Slope, and Vegetation) and secondary data derived from the records of turtle conservation groups and related agencies. This research was carried out on 24 June 05 August 2019. The results of this research are the range of beach slopes reaching 10.5\% $26 \%$ with an average of $16.3 \%$ still in the category of somewhat steep, for comparison of sand composition in natural and semi-natural nests $92.94 \%$ \& $96.34 \%$, vegetation found around the coast is pine shrimp (Casuarina Equisetifolia) and Pandan Laut (Pandanus sp.), Coconuts (Cocos Nucifera) and Katang-Katang (Ipomoea pes-caprae). Temperature when observed for a week has a range of $25^{\circ}-28^{\circ}$ this can affect the sex of the hatchlings that will hatch and the length of incubation in the Semi-Natural nest
\end{abstract}

Keywords: Spawning Habitat; Lekang Turtle; Lepidochelys olivaceae, Mapak Indah Beach

\section{PENDAHULUAN}

Pantai Mapak merupakan pantai yang masih di gemari oleh penyu untuk mendarat, khususnya penyu dengan nama lokal Lekang (Lepidochelys olivaceae). Pantai ini terletak di Kota Mataram, Nusatenggara Barat tepatnya ada di Kecamatan Sekarbela, merupakan salah satu pantai wisata yang sering di kunjungi oleh masyarakat local untuk menghabiskan waktu mereka. 
Pantai yang memiliki pasir hitam dengan gelombang yang sedikit tenang serta memiliki kemiringan yang tidak begitu curam merupakan habitat peneluran yang di sukai oleh penyu jenis ini untuk bertelur.

Pengelolaan di pantai Mapak masih secara tradisional dengan dikelola oleh warga sekitar. Pemilik lahan mendirikan Kelompok Pelestari Penyu Mapak (KP2M) yang resmi dibentuk pada tanggal 7 September 2017 dan dilegalkan melalui Surat Keterangan Walikota SK/No. 957/VII/2018. Selain konsen pada konservasi penyu, Kelompok ini juga sedang melakukan pembangunan wisata Pantai Mapak yang didanai oleh PT. PLN (Persero) Kota Mataram. Infrastruktur yang ada di Pantai Mapak diantaranya ada kolam penangkaran penyu atau tukik, sarang semi alami penangkaran telur penyu, pos pusat informasi, toilet, gazebo, tempat pedagang, dan beberapa bangunan lain yang masih dalam tahap pembangunan. Saat ini Kelompok Pelestari Penyu Mapak masih menata dan melakukan studi banding ke tempat konservasi penyu lain.

Kekayaan alam Indonesia berupa terumbu karang, padang lamun dan pantai berpasir merupakan habitat alami yang sangat baik bagi kelangsungan hidup penyu. Penyu memanfaatkan kawasan pantai berpasir sebagai tempat persinggahan dan melakukan aktifitas biologi seperti bersarang dan bertelur. Terdapat tujuh spesies penyu yang hidup di dunia, enam diantaranya dapat ditemukan di perairan Indonesia. Salah satu penyu yang hidup di perairan Indonesia adalah penyu lekang (Lepidochelys olivaceae). Tiap tahunnya populasi spesies ini terus menurun, untuk itu dikategorikan satwa langka dan dilindungi dalam Red Data Book IUCN yang termasuk dalam Apendix I CITES (Wicaksono et al., 2013). Penelitan penyu di Indonesia yang pernah dilakukan Lepidochelys olivacea di Bali (Suraeda et al., 2018 Ayuningtyas et al., 2019), Penyu Lekang (Rofiah et al., 2012).

Penyu merupakan salah satu fauna yang di lindungi karena populasinya yang terancam punah, di Indonesia terdapat enam spesies penyu dari tujuh yang ada di dunia. Kondisi inilah yang menyebabkan semua jenis penyu di Indonesia diberikan status dilindungi oleh Negara sebagaimana tertuang dalam Permen RI No. 7 pada tahun 1999 mengenai pengawetan jenis-jenis tumbuhan dan satwa yang di lindungi penyu secara internasional termasuk satwa appendix 1. Satwa yang termasuk dalam appendix 1 di larang untuk di perdagangkan.

Pantai Mapak membentang sepanjang 1700 meter berada pada kota Mataram kecamatan Ampenan, memiliki karakteristik pantai yang berpasir hitam yang sangat di sukai oleh penyu Lekang (Lepidochelys olivaceae). Penyu memiliki dua famili yaitu, Cheloniidae dan Dermochelyidae. Penyu lekang (Lepidochelys olivacea) termasuk kedalam famili Cheloniidae. Salah satu ciri dari $L$. olivacea yakni memiliki ukuran tubuh yang relative lebih kecil dibandingkan dengan kelompok penyu lainnya. Karapas L. olivacea memiliki warna abu - abu, sedangkan pada bagian bawah tubuh (plastron) L. olivacea memiliki warna krem keabuan. Bobot Lepidochelys olivacea berkisar antara $50 \mathrm{~kg}$ hingga $75 \mathrm{~kg}$ dengan panjang tubuh 150 sentimeter. Sementara bobot tukik Lepidochelys olivacea 16 gram hingga 19 gram dengan panjang rata-rata karapas tukik hingga $44 \mathrm{~mm}$. Penyu lekang bermigrasi disepanjang perairan dengan kedalaman menyelam hingga 150 meter. Pantai pasir dengan kemiringan landai merupakan tempat bertelur penyu yang dapat ditemukan di pantai-pantai di Indonesia (Purnama et al., 2013).

\section{MATERI DAN METODE}

Penelitian ini dilaksanakan pada bulan Juni - Agustus 2019. Pengambilan data parameter Bio-Fisik dilaksanakan pada 24 Juni - 05 Agustus 2019 di Perairan Pantai Mapak Indah, Kota Mataram, Nusatenggara Barat. Lokasi penelitian berada di 5 stasiun dan dapat dilihat pada peta seperti yang terlihat (Gambar 1).

Kemiringan pantai diukur menggunakan tali rafia sepanjang $2 \mathrm{~m}$ untuk mengukur panjang, Kayu berukuran $2 \mathrm{~m}$ untuk mendapatkan ketinggian dan penggaris siku untuk mempertahankan kelurusan tali. Pengukuran dimulai dari batas Foreshore. Nilai kemiringan dapat dihitung menggunakan rumus trigonometri (Putra, 2014).

$$
\text { Rumus kemiringan ; Kemiringan }(\%)=\left(\frac{a}{b}\right) \times 100 \%
$$


Keterangan: a $=$ tinggi tongkat sampai batas tali yang diikat sampai membentuk sudut $90^{\circ}$ terhadap tongkat; $b=$ panjang tali berskala.

Suhu dan kelembaban sarang diukur dengan menggunakan Termo Hygrometer digital pada sarang-semi. Pengukuran dilakukan pada substrat bawah permukaan sedalam $\pm 30 \mathrm{~cm}$ dilakukan selama 7 hari kemudian mencatat hasilnya. Pengamatan suhu dan kelembaban substrat diharapkan dapat mewakili kondisi suhu dan kelembaban substrat dalam sarang telur penyu.

Tekstur sedimen berguna untuk pendugaan kerapatan sedimen yang ada di sekitar sarang penyu. Analisis untuk mendapatkan ukuran butir meliputi analisis ayakan dan klasifikasi Wentworth. Metode pengayakan substrat sedimen dilakukan dengan cara penyaringan (sieve) menggunakan sieve shaker. (Putra, 2014).

Parameter vegetasi di dapatkan melalui observasi langsung ke lapang, dengan melihat vegetasi yang ada di pantai Mapak Indah serta mengambil gambarnya guna mencocokannya pada buku spesies mangrove dan sumber dari jurnal yang tersedia.

\section{HASIL DAN PEMBAHASAN}

Pantai Mapak merupakan pantai pariwisata yang cukup padat, dengan berdampingan dengan aktifitas nelayan yang menagnkap ikan menyandarka kapalnya di sepajang garis pantai, pantai berpasir hitam, dengan matapencarharian masyarakatnya mencari ikan dan berjualan makanan olahan ikan dan ada beberapa yang berternak Bebek dan Sapi. Memiliki gelombang yang relative lebih tenang. Banyak aktivitas Nelayan memancing dimalam hari yang di kawatirkan akan mengganggu proses peneluran penyu.

Berdasarkan hasil pengukuran dilapangan diketahui bahwa nilai kemiringan Pantai Mapak Indah pada tiap lokasi berkiasar antara 10,5-26\%. Menurut Darmawijaya (1997) nilai kemiringan sebesar 10,5\%, 12\%, 16\% menunjukkan kategori Miring, nilai kemiringan sebesar dan nilai kemiringan sebesar $26 \%$ menunjukkan kategori agak curam. Hasil pengukuran kemiringan Pantai Mapak Indah tiap stasiun dapat dilihat pada tabel 2. Semakin curam pantai maka akan semakin besar pula energi penyu yang diperlukan untuk naik bertelur, dan semakin sulit penyu melihat objek yang berada jauh di depan, karena mata penyu hanya mampu berakomodasi dan melihat dengan baik pada sudut $150^{\circ}$ ke bawah (Yusuf, 2000).

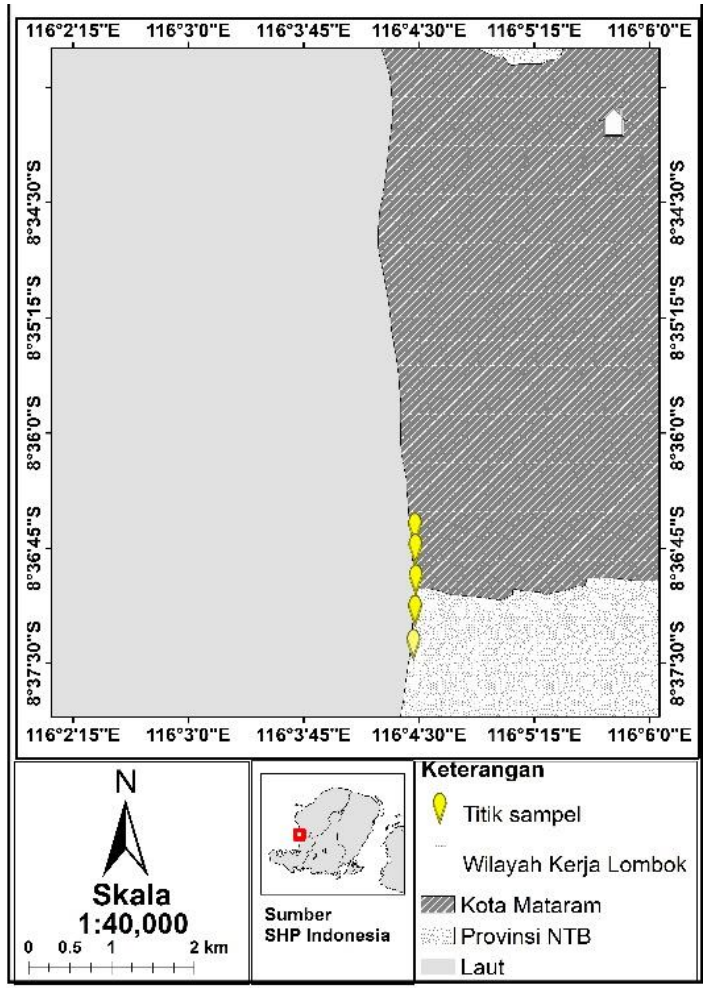

Gambar 1. Lokasi Penelitian 
Hasil pengukuran sarang Semi-Alami memiliki rentang suhu rata-rata perhari selama pengamatan adalah $25^{\circ}-28^{\circ}$ hal ini dapat mempengaruhi jenis kelamin Tukik yang akan menetas serta lama inkubasinya di dalam sarang Semi-Alami. Suhu yang layak bagi perkembangan embrio telur penyu adalah antara $24-33^{\circ} \mathrm{C}$ Suhu juga akan menentukan rasio kelamin anak penyu, penyu yang lahir dari sarang yang suhu inkubasinya antara $28-29^{\circ} \mathrm{C}$ kemungkinan besar akan menghasilkan penyu berkelamin jantan sedangkan suhu inkubasinya antara $30-31^{\circ} \mathrm{C}$ kemungkinan besar akan menghasilkan penyu berkelamin betina. (Putra, 2014). Dari pengukuran kelembaban di Pantai Mapak Indah seperti di tujukan pada Gambar 4. Pengamatan yang dilakukan selama 7 hari menghasilkan data pengukuran kelembaban berkisar antara 64-75\%, hal ini merupakan kelembaban yang optimum bagi sarang penyu, seperti pernyataan dari Andamari (1981) menambahkan perlakuan untuk kelembaban yang optimum adalah sekitar $60 \%$.

Pasir Pantai Mapak Indah memiliki jenis pasir berwarna Hitam. Tekstur substrat dari sarang alami dan sarang semi-alami di Pantai Mapak Indah didominasi oleh pasir, yaitu lebih dari $90 \%$ dan selebihnya kerikil dan Lanau dengan jumlah yang sangat kecil. Urutan ukuran sampel pasir substrat semi-alami di Pantai Mapak Indah adalah pasir sangat kasar dengan persentase kandungan berkisar antara $24,48 \%$, pasir kasar dengan persentase kandungan berkisar antara $22,59 \%$, pasir sedang dengan pers kandungan berkisar antara 48,81\%, pasir halus dengan persentase kandungan berkisar antara $16,39 \%$, pasir sangat halus dengan persentase kandungan berkisar antara 16,39\% data komposisi dapat dilihat pada Tabel 3.

Susunan tekstur berupa pasir tidak kura ng dari 90\% dengan diameter butiran berbentuk sedang dan halus, sisanya adalah debu dan liat (Acevedo et al., 2009). Tekstur kasar bersifat lebih mengalirkan air daripada menampung air karena pasir bertekstur kasar memiliki pori yang lebih besar. Substrat yang berukuran sedang sesuai untuk habitat penyu (Ackerman, 1997).

Tabel 1. Nilai Kemiringan

\begin{tabular}{lllll}
\hline Stasiun & $\mathrm{a}(\mathrm{cm})$ & $\mathrm{b}(\mathrm{cm})$ & Miring $(\%)$ & Kelas \\
\hline ST. 1 & 52 & 200 & 26 & Agak Curam \\
ST. 2 & 32 & 200 & 16 & Miring \\
ST. 3 & 34 & 200 & 17 & Agak Curam \\
ST. 4 & 21 & 200 & 10.5 & Miring \\
ST. 5 & 24 & 200 & 12 & Miring \\
\hline
\end{tabular}

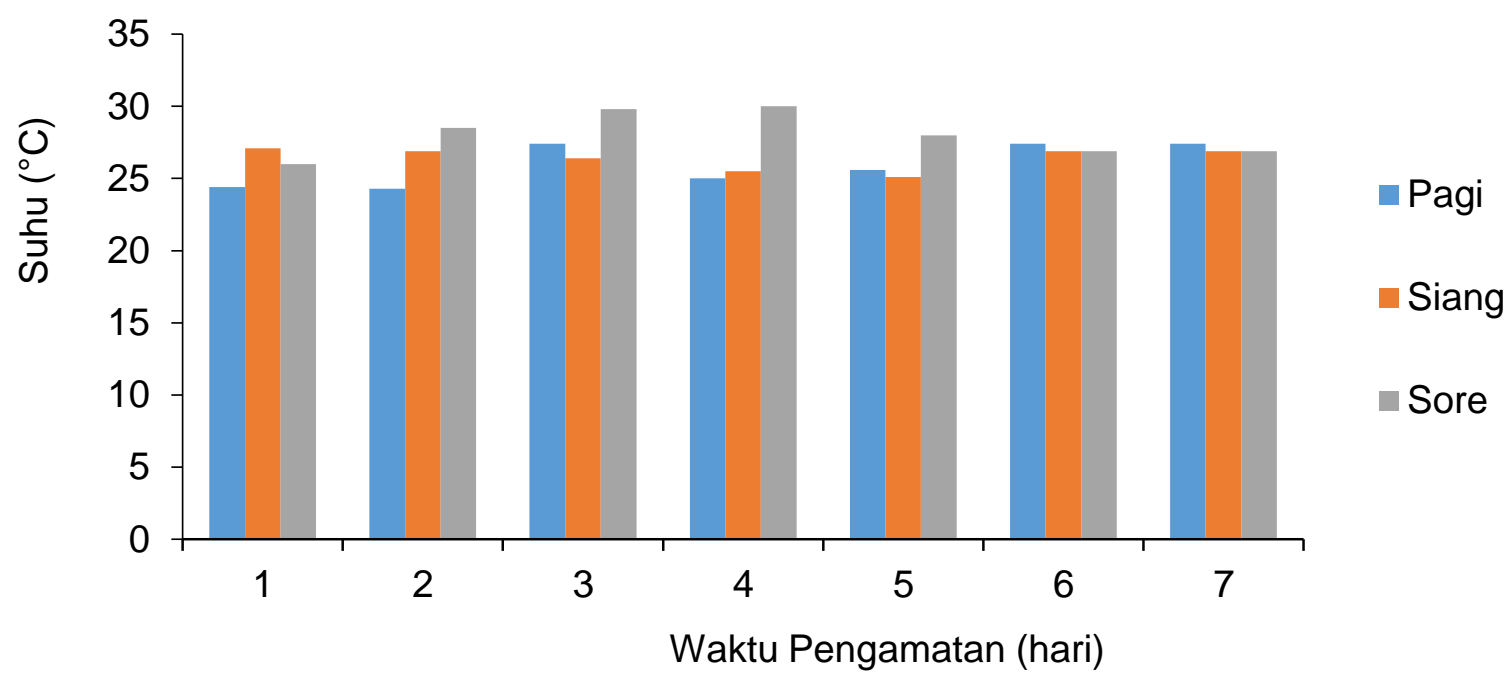

Gambar 1. Grafik Suhu harian 
Tumbuhan pada pantai mempunyai peranan yang sangat penting bagi penyu untuk melindungi sarang telur, agar tidak terkena langsung oleh sinar matahari. Selain itu vegetasi dapat mencegah perubahan suhu yang tajam di sekitar sarang dan melindungi sarang dari gangguan predator, serta memberikan pengaruh terhadap kelembaban, kestabilan pada pasir (Kurniawan et al., 2015). Selama Observasi vegetasi yang sering di jumpai di sekitar Utara mapak adalah jenis , vegetasi yang sering di jumpai adalah cemara Udang (Casuarina Equisetifolia) gambar 9 (a), Pandan Laut (Pandanus sp.) gambar 9 (b), kelapa (Cocos Nucifera) gambar 9 (c), dan Katangkatang (Ipomoea pes-caprae) gambar 9 (d). Contoh dari hasil vegetasi di Pantai Mapak penulis menyajikan pada gambar 5 .

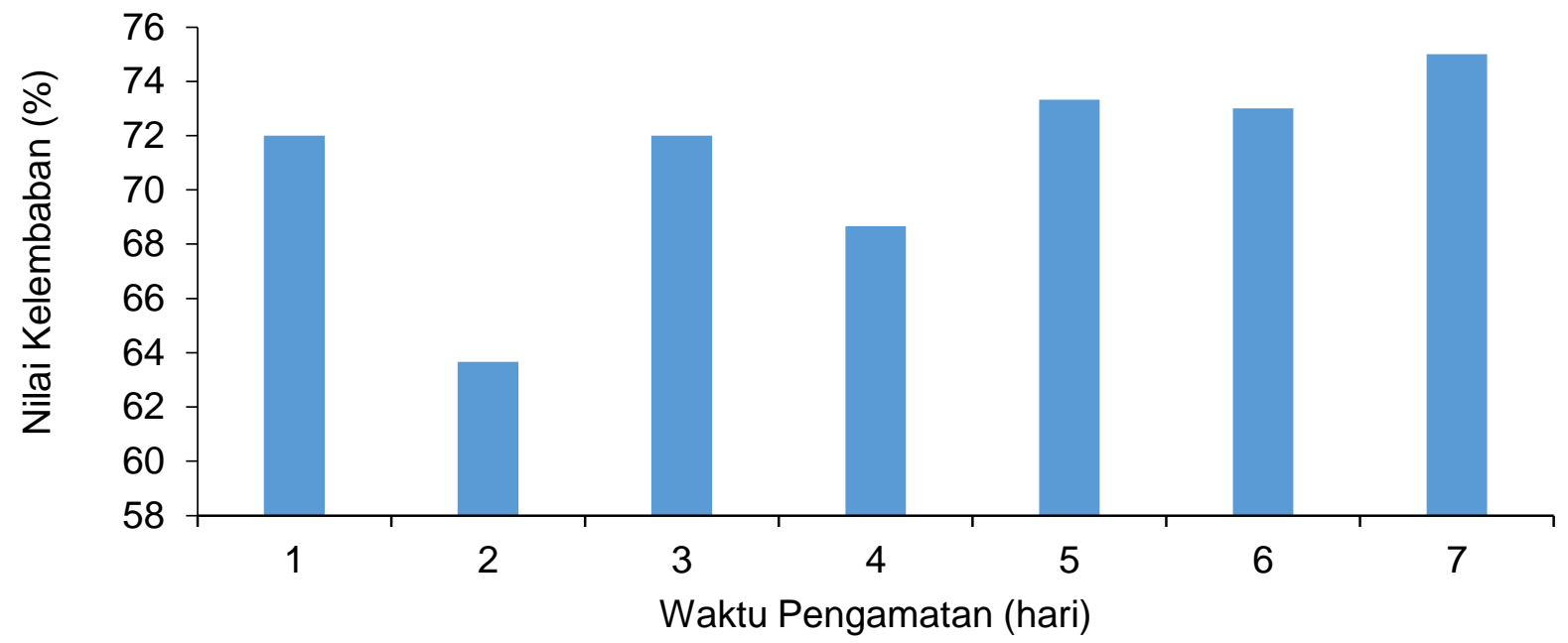

Gambar 2. Grafik Kelembaban

Tabel 2. Komposisi Sedimen

\begin{tabular}{lcccc}
\hline \multirow{2}{*}{ Letak } & \multicolumn{3}{c}{ Fraksi (\%) } & \multirow{2}{*}{ Total } \\
\cline { 2 - 4 } & Kerikil & Pasir & Lanau & 100 \\
Alami & 0,26 & 92,94 & 6,80 & 100 \\
\hline
\end{tabular}

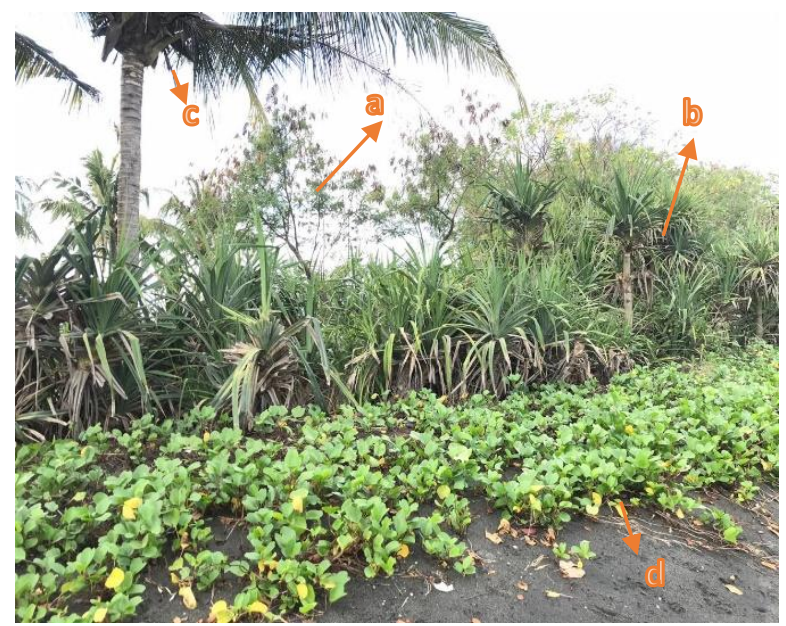

Gambar 3. Vegetasi Pantai Mapak 


\section{KESIMPULAN}

Karakteristik habitat peneluran penyu Lekang di Pantai Mapak Indah memiliki panjang pantai \pm 1.700 Meter, dengan rata - rata kemiringan pada pantai Mapak Indah adalah $16 \%$, kemiringan terendah ada pada stasiun 5dengan nilai $12 \%$ (Miring) yang berada pada lapangan di sebelah selatan pantai Mapak namun sudah tidak pernah di temukan adanya penyu mendarat, di stasiun 1 dengan kemiringan $26 \%$ (agak curam) masih menjadi tempat paling favorit untuk mendarat karena masih. Suhu sarang semi-alami di Mapak berkisar antara $25^{\circ} \mathrm{C}-28^{\circ} \mathrm{C}$, Kelembaban rata-rata pada sarang semi mencapai $71 \%$, sementara komposisi sedimen termasuk dalam pasir dengan $96,34 \%$ pasir, 3,34\% Lanau dan 0,32\% kerikil. Hasil dari nilai kelembaban berkisar antara $64-75 \%$, hal ini merupakan kelembaban yang optimum bagi sarang penyu. vegetasi yang sering di jumpai adalah cemara Udang (Casuarina Equisetifolia), Pandan Laut (Pandanus sp.), kelapa (Cocos Nucifera), dan Katang-katang (Ipomoea pes-caprae)

\section{UCAPAN TERIMAKASIH}

Terima kasih disampaikan kepada Balai Pengelolaan Pesisir dan Laut (BPSPL) Denpasar, wilayah kerja Nusa Tenggara Barat membantu selama penelitian.

\section{DAFTAR PUSTAKA}

Ackerman, R.A. 1997. The nest environment and the embryonic development of sea turtles. The Biology of Sea Turtles. Lutz, P.L., and J.A. Musick (Eds.). Florida (US): CRC Press. p 83-106.

Ayuningtyas, I., Kushartono, E.W., \& Redjeki, S. 2019. Identifikasi Jamur pada Tukik Lepidochelys olivacea, Eschscholtz, 1829 (Reptilia : Cheloniidae) Di Turtle Conservation And Education Center Bali. Journal of Marine Research, 8(2):157-167. doi: 10.14710/jmr.v8i2.25096

Darmawijaya, M.I. 1997. Klasifikasi Tanah Dasar Teori bagi Peneliti Tanah dan Pelaksana Pertanian di Indonesia. Gadjah Mada University Press, Yogyakarta.

Maulany, R.I., Booth, D.T. \& Baxter, G.S. 2012. The effect of incubation temperature on hatchling quality in the olive ridley turtle, Lepidochelys olivacea, from Alas Purwo National Park, East Java, Indonesia: implications for hatchery management. Marine Biology, 159:2651-266

Miller, J.D. 1997. Reproduction In Sea Turtles. Lutz, P.L dan Musick, J.A (eds). The Biology of Sea Turtle. CRC Press, Boca. Raton.

Putra, B.A., Wibowo, E. \& Redjeki, S. 2014. Studi Karakteristik Biofisik Habitat Peneluran Penyu Hijau (Chelonia mydas) di Pantai Paloh Sambas, Kalimantan Barat. Journal of Marine Research, 3(3):173-181

Rofiah, A., Hartati, R., \& Wibowo, E. 2013. Pengaruh Naungan Sarang terhadap Persentase Penetasan Telur Penyu Lekang (Lepidochelys olivacea) di Pantai Samas Bantul, Yogyakarta. Journal of Marine Research, 1(2):103-108. doi: 10.14710/jmr.v1i2.2026

Suraeda, R.Y., Sunaryo, S., \& Kushartono, E.W. 2018. Laju Pertumbuhan Spesifik Tukik Penyu Lekang (Lepidochelys olivacea) dengan Pemberian Pakan Buatan Yang Berbeda di Turtle Conservation And Education Center, Bali. Journal of Marine Research, 7(3):185-192. doi: 10.14710/jmr.v7i3.25908

Wicaksono, M.A., Elfidasari, D. \& Kurniawan, A. 2013. Aktivitas Peletarian Penyu Hijau (Chelonia mydas) Di Taman Pesisir Pantai Penyu Pangumbahan Sukabumi Jawa Barat. Universitas Al Azhar, Jawa Barat.

Yusuf, A. 2000. Mengenal Penyu. Yayasan Alam Lestari. Jakarta. 